\title{
Refractive Surprise in Post-Cataract Surgery in Post Epi-LASIK Patient: A Lesson Learnt
}

\author{
Md-Muziman-Syah $M M^{a}$, Mutalib $H A^{b}$, Khairidzan $M K^{c}$, Noorhazayti $A H^{d}$ \\ ${ }^{a}$ Department of Optometry and Visual Science, Kulliyyah of Allied Health Sciences, International Islamic \\ University Malaysia, 25200 Kuantan, Pahang, Malaysia. \\ bProgramme of Optometry and Visual Science, Faculty of Health Sciences, Universiti Kebangsaan Malaysia, \\ Jalan Raja Muda Abdul Aziz, 50300 Kuala Lumpur, Malaysia. \\ 'Department of Ophthalmology, Kulliyyah of Medicine, International Islamic University Malaysia, 25200 \\ Kuantan, Pahang, Malaysia. \\ ${ }^{\mathrm{d} D e p a r t m e n t}$ of Paediatric Dentistry and Dental Public Health, Kulliyyah of Dentistry, International Islamic \\ University Malaysia, 25200 Kuantan, Pahang, Malaysia.
}

\section{ABSTRACT}

Post-myopic laser refractive surgery corneal power measurement for intraocular lens power calculation is one of the most challenging issues in cataract surgery. Standard keratometry measurement is likely to be overestimated which could lead to false-low intraocular lens power. As a result, this can lead to hyperopic surprise. Contact lens method is an alternative method which is relatively inexpensive and accessible procedure in many optometry and ophthalmology centres. The contact lens method with optimised equations have been used for this case to obtain an accurate postoperative corneal power.

KEYWORDS: post-myopic laser refractive surgery, corneal power, contact lens method, $C L M_{\text {mod }}$

\section{INTRODUCTION}

This article presents a case of post-myopic laser refractive surgery which subsequently developed cataract. The determination of postoperative corneal power $\left(K_{\text {post }}\right)$ was calculated using two optimised equations; the modified contact lens method equation $\left(C L M_{\bmod }\right)$ and the regression contact lens method equation $\left(\mathrm{CLM}_{\mathrm{reg}}\right){ }^{1}$

\section{CASE REPORT}

A 35-year-old gentleman had undergone bilateral epithelial laser in-situ keratomileusis (Epi-LASIK). From the patient's pre Epi-LASIK medical record, the manifest refraction in the right eye (RE) and

Corresponding Author:

Asst. Prof. Dr. Md Mustafa Md-Muziman-Syah

Department of Optometry and Visual Science

Kulliyyah of Allied Health Sciences

International Islamic University Malaysia

25200 Kuantan, Pahang

Malaysia.

Tel No : +609-5706400 (ext:3397)

Email : syah@iium.edu.my left eye (LE) were $-5.25 /-1.00 \times 20$ and $-5.25 /$ $1.75 \times 180$, respectively, with corrected distance visual acuity (CDVA) of $6 / 6$ in both eyes. At 6 -month follow-up, the uncorrected distance visual acuity (UDVA) were $6 / 6$ in both eyes. However, at 12month follow-up, the RE developed anterior capsular cataract. The UDVA in the RE and LE were $6 / 21$ and 6/7.5, respectively. The manifest refraction in the RE and LE were $-1.50 /-0.50 \times 30$ (CDVA: $6 / 7.5^{-3}$ ) and $-0.25 /-0.50 \times 85$ (CDVA: 6/6), respectively. Five-month later, the UDVA and pinhole UDVA in the RE has reduced to $6 / 36$ and $6 / 18$, respectively.

Phacoemulsification was performed in the RE. The implanted intraocular lens (IOL) was a +21 D CT ASPHINA 509MP (Zeiss Meditec, Oberkochen, Germany) which was aimed for emmetropia. The IOL power was determined using the IOL calculator for eyes with prior myopic LASIK/PRK/RK. ${ }^{2}$ The average IOL power for all available formulas was $20.99 \mathrm{D}$. On day 7 post-phacoemulsification, the RE UDVA was 6/60. Three-month later, the RE UDVA remained at $6 / 48$ and the refraction was $-2.00 \mathrm{D}$ (CDVA: 6/6). 


\section{Back-Calculated IOL Power}

We carried out the back-calculation method to investigate the actual IOL power needed according to 1.00 D of IOL prediction error which produced $0.70 \mathrm{D}$ of refractive error at spectacle plane. ${ }^{3}$ As the actual postoperative refractive error was $-2.00 \mathrm{D}$, thus the IOL prediction error was $2.86 \mathrm{D}$ and the required IOL power to achieve emmetropia was +18.14 D.

The IOL power was re-calculated using $K_{\text {post }}$ obtained from the historical method (HM), ${ }^{4} \mathrm{CLM}_{\bmod }{ }^{1}$ and $\mathrm{CLM}_{\text {reg, }},{ }^{1}$ with the SRK/T and Holladay 1 formulas. The IOL power to achieve emmetropia was calculated with Aconstant of 118.3 for SRK/T and surgeon factor (SF) of 1.39 for Holladay $1 .{ }^{5}$ Data for $K_{\text {post }}$ calculations are listed in Table 1.

\section{DISCUSSION}

In the eye that had undergone laser refractive surgery, miscalculation of IOL power prior to cataract surgery can lead to reduced vision. ${ }^{7}$ Sources of the error are namely incorrect $K_{\text {post }}$, axial length and use of inappropriate $\mathrm{IOL}$ power formula. ${ }^{8}$ Past literatures had reported that inaccurate estimation of $K_{\text {post }}$ was the main error ${ }^{3,7}$ because the laser refractive surgery altered central region of anterior corneal while retaining the posterior corneal.

The $\mathrm{HM}$ is preferred to determine $K_{\text {post }}$ for IOL power calculation when the pre-laser refractive surgery data are available. $^{3}$ If the preoperative data are unavailable and CDVA 6/21 or better, the CLM can be considered $^{9}$ with modification to obtain a more accurate result. ${ }^{1}$ Therefore, in this case, we applied the $C L M_{\text {mod }}$ and $C L M_{\text {reg }}$ equations. ${ }^{1}$

To achieve the emmetropic target, the backcalculated IOL power was $+18.14 \mathrm{D}$. It showed that the IOL power calculated using the combination of the $\mathrm{HM}$ and Holladay 1 formulas produced a more accurate IOL power result. Whereas, the combination with the SRK/T formula tended to give a lower IOL power which could cause an unwanted postoperative hyperopic. This finding was consistent with the previous report where it was also found that the combination of the HM and SRK/T formulas tended to produce hyperopic side of postoperative refraction. ${ }^{10}$ As an alternative method, the combination of the CLM mod and Holladay 1 formulas provided an accurate IOL power result with predicted postoperative refractive error of $-0.06 \mathrm{D}$ only, which was almost emmetropic. However, the CLM res provided steeper postoperative corneal power than the $\mathrm{HM}$ and $C L M_{\text {mod }}$ values. The steeper value of the $C^{2} M_{\text {reg }}$ gives a false-low IOL power that leads to hyperopic surprise. Thus, in the situation where preoperative keratometric and refraction data are unavailable, the $C L M_{\text {reg }}$ can be used with caution. It is because the $\mathrm{CLM}_{\text {reg }}$ uses similar adjustment for all eyes.

This current finding suggests that the CLM mod is able to produce an accurate $K_{\text {post }}$ and subsequently IOL power when it is combined to the Holladay 1 formula with the axial length of 23.50 to $25.99 \mathrm{~mm}^{4}$ We recommend using a flatter corneal power for IOL power calculation and add +0.25 $\mathrm{D}$ to the obtained IOL power to prevent hyperopic surprise. For this case study, we suggest $+18.50 \mathrm{D}$ of IOL power with predicted postoperative refractive error of approximately $-0.25 \mathrm{D}$ of myopic.

\section{CONCLUSION}

The $C L M_{\text {mod }}$ equation is able to determine an accurate corneal power in cataract patient who had previously undergone laser refractive surgery. We believe that large prospective research is needed to validate the accuracy of the CLM mod in determining corneal power for IOL power calculation in cataract patient with a history of laser refractive surgery.

\section{CONFLICT OF INTEREST}

There is no conflict of interest to be declared.

\section{ACKNOWLEDGEMENT}

Special appreciation to the International Islamic University Malaysia for financially supporting this project (RIGS 16-129-0293). 
Table I: Right eye data of 35-year-old gentleman after Epi-LASIK for myopia who had subsequent cataract surgery

\begin{tabular}{|c|c|}
\hline Parameter & Right Eye \\
\hline $\begin{array}{r}K_{\text {pre }} \text { Topographer } \\
\mathrm{SE}_{\text {pre (spectacle plane) }} \\
\mathrm{SE}_{\text {post (spectacle plane) }} \\
\text { SE Change } \\
K_{\text {post-pre (corneal plane) }} \text { Topographer } \\
K_{\text {post }} \text { IOLMaster } \\
K_{\text {post }} \mathrm{HM} \\
K_{\text {post }} \text { CLM } M_{\text {mod }} \\
K_{\text {post }} \text { CLM } M_{\text {reg }} \\
\text { Axial Length } \\
\text { Anterior Chamber Depth } \\
\text { Target Refraction }\end{array}$ & $\begin{array}{l}45.29 \text { / } 43.76 \mathrm{D} \\
-5.75 \mathrm{D} \\
-1.75 \mathrm{D} \\
3.67 \mathrm{D} \\
41.47 \text { / } 40.26 \mathrm{D} \\
40.52 \text { / } 40.23 \mathrm{D} \\
40.85 \mathrm{D} \\
40.81 \mathrm{D} \\
40.95 \mathrm{D} \\
25.35 \mathrm{~mm} \\
3.72 \mathrm{~mm} \\
\text { Emmetropia }\end{array}$ \\
\hline $\begin{array}{r}\text { Lens Constant } \\
\text { A-Constant } \\
\text { SF }\end{array}$ & $\begin{array}{l}118.30 \\
1.39\end{array}$ \\
\hline $\begin{array}{r}\text { Suggested TOL Power using } K_{\text {post }} \mathrm{HM} \\
\text { SRK } / \mathrm{T} \\
\text { Holladay } 1\end{array}$ & $\begin{array}{l}17.78 \mathrm{D} \\
18.16 \mathrm{D}\end{array}$ \\
\hline $\begin{array}{r}\text { Suggested IOL Power using } K_{\text {post }} \mathrm{CLM}_{\text {mod }} \\
\text { SRK/T } \\
\text { Holladay } 1\end{array}$ & $\begin{array}{l}17.83 \mathrm{D} \\
18.22 \mathrm{D} \\
\end{array}$ \\
\hline $\begin{array}{r}\text { Suggested TOL Power using } K_{\text {post }} \mathrm{CLM}_{\text {reg }} \\
\text { SRK/T } \\
\text { Holladay } 1\end{array}$ & $\begin{array}{l}16.59 \mathrm{D} \\
16.85 \mathrm{D}\end{array}$ \\
\hline $\begin{array}{r}\text { Expected Error in IOL Calculation using } K_{\text {post }} H M \\
\text { SRK/T } \\
\text { Holladay } 1\end{array}$ & $\begin{array}{r}0.36 \mathrm{D} \\
-0.02 \mathrm{D} \\
\end{array}$ \\
\hline $\begin{array}{r}\text { Expected Error in TOL Calculation using } K_{\text {post }} \text { CLM mod } \\
\text { SRK } / T \\
\text { Holladay } 1\end{array}$ & $\begin{array}{r}0.31 \mathrm{D} \\
-0.08 \mathrm{D}\end{array}$ \\
\hline $\begin{array}{r}\text { Expected Error in IOL Calculation using } K_{\text {post }} C_{\text {SMM }} \\
\text { SRK/T } \\
\text { Holladay } 1\end{array}$ & $\begin{array}{l}1.55 \mathrm{D} \\
1.29 \mathrm{D}\end{array}$ \\
\hline
\end{tabular}

(-ve) sign of expected error = suggested IOL > required IOL for emmetropia (18.14 D)

$\mathrm{SE}_{\text {pre }}=$ spherical equivalent pre Epi-LASIK

$\mathrm{SE}_{\text {post }}=$ spherical equivalent post Epi-LASIK

SE Change post-pre $_{\text {s }}$ spherical equivalent change (amount of refractive change induced by Epi-LASIK)

$K_{\text {pre }}=$ keratometric value pre Epi-LASIK

$K_{\text {post }}=$ keratometric value post Epi-LASIK

The $K_{\text {post }}$ calculation details using the original contact lens method (CLM), CLM mod, CLM reg and HM are as follows;

Base curve of contact lens $(C L), C_{B C}$

$=42.19 \mathrm{D}$

Spherical power of $\mathrm{CL}, \mathrm{C}_{\mathrm{Rx}}$

$=-3.00 \mathrm{D}$

Spherical equivalent (SE) with $\mathrm{CL}$ at corneal plane, $\mathrm{R}_{\mathrm{CL}}$

$=\quad+0.13 \mathrm{D}$

SE without $\mathrm{CL}$ at corneal plane, $\mathrm{R}_{0}$

$=-1.71 \mathrm{D}$

$$
\begin{array}{ll}
K_{\text {post }} \mathrm{CLM} & =\mathrm{C}_{\mathrm{BX}}+\mathrm{C}_{\mathrm{Rx}}+\mathrm{R}_{\mathrm{CL}}-\mathrm{R}_{0} \\
K_{\text {post }} \mathrm{CLM} & =42.19+(-3.00)+0.13-(-1.71) \\
& =41.03 \mathrm{D} \\
K_{\text {post }} \mathrm{CLM} \text { mod } & =\mathrm{CLM}-0.312[\mathrm{SE} \text { Change } \\
\left.K_{\text {post }} \mathrm{CL} M_{\text {mod }}\right]+0.922 \\
& =41.03-0.312[3.67]+0.922 \\
& =40.81 \mathrm{D} \\
K_{\text {post }} \mathrm{CLM}_{\text {reg }} & =1.179[\mathrm{CLM}-7.423 \\
K_{\text {post }} \mathrm{CLM} \text { reg } & =1.179[41.03]-7.423 \\
& =40.95 \mathrm{D} \\
K_{\text {post }} \mathrm{HM} & =\mathrm{K}_{\text {pre }}-\mathrm{SE} \text { Change } \\
K_{\text {post }} \mathrm{HM} & =44.52-3.67 \\
& =40.85 \mathrm{D}
\end{array}
$$




\section{REFERENCES}

1. Md-Muziman-Syah MM, Mutalib HA, Sharanjeet Kaur MS, Khairidzan MK. New modified equation of contact lens method in determining post myopic laser refractive surgery corneal power. Int Med J Malaysia 2016;15:61-8.

2. Hill W, Wang L, Koch DD. IOL power calculation in eyes that have undergone LASIK/PRK/RK: IOL calculator for eyes with prior myopic LASIK/ PRK. The Alcon Laboratories and ASCRS Foundation. Available from: http://iolcalc.org/ wbfrmCalculator.aspx. Accessed on 2018 Oct 30.

3. Yang R, Yeh A, George MR, Maria R, Boerman H, Wang M. Comparison of intraocular lens power calculation methods after myopic laser refractive surgery with previous refractive surgery data. J Cataract Refract Surg 2013;39:1327-35.

4. Hoffer KJ. Intraocular lens power calculation for eyes after refractive keratotomy. J Refract Surg 1995;11:490-517.

5. Aristodemou P, Cartwright NEK, Sparrow JM, Johnston RL. Formula choice: Hoffer Q, Holladay 1 , or SRK/T and refractive outcomes in 8108 eyes after cataract surgery with biometry by partial coherence interferometry. J Cataract Refract Surg 2011;37:63-71.

6. Holladay JT. Cataract surgery in patients with previous keratorefractive surgery (RK, PRK, and LASIK). Ophthalmic Practice 1997;15:238-44.

7. Savini G, Hoffer KJ. Intraocular lens power calculation in eyes with previous corneal refractive surgery. Eye Vis (Lond). $2018 \mathrm{Jul}$ 8;5:18.

8. Olsen T. Calculation of IOL power: a review. Acta Ophthalmol Scand 2007;85:472-85.

9. Zeh WG, Koch DD. Comparison of contact lens overrefraction and standard keratometry for measuring corneal curvature in eyes with lenticular opacity. J Cataract Refract Surg 1999;25:898-903.

10. Taheri SMR, Kheiltash A, Hashemi $\mathrm{H}$. Comparison of corneal power and intraocular lens power calculation methods after LASIK for myopia. Iranian J Ophthal 2009;21:45-54. 